\title{
SEED TREATMENT WITH PACLOBUTRAZOL AFFECTS EARLY GROWTH, PHOTOSYNTHESIS, CHLOROPHYLL FLUORESCENCE AND PHYSIOLOGY OF RICE
}

\author{
HUANG, S. ${ }^{1,2 \#}-$ LUO, H. ${ }^{1,2 \#}-$ ASHRAF, U. $.^{1,2,3}-$ ABRAR, M. ${ }^{4}-$ HE, L. ${ }^{1,2}-$ ZHENG, A. $^{1}-$ WANG, ${ }^{5}$ \\ ZHANG, T. ${ }^{1,2}-$ TANG, X. ${ }^{1,2 *}$
}

${ }^{I}$ Department of Crop Science and Technology, College of Agriculture, South China Agricultural University, Guangzhou 510642, PR China

${ }^{2}$ Scientific Observing and Experimental Station of Crop Cultivation in South China, Ministry of Agriculture, Guangzhou 510642, PR China

${ }^{3}$ Department of Botany, University of Education (Lahore), Faisalabad-Campus, Faisalabad 38000, Pakistan

${ }^{4}$ State Key Lab. Grassland Argo-Ecosystem, School of Life Sciences, Lanzhou University, Lanzhou, Gansu 730000, PR China

${ }^{5}$ Key Laboratory of Key Technology for South Agricultural Machine and Equipment, Ministry of Education, Guangzhou 510642, PR China

${ }^{\#}$ These author have contributed equally to this work.

\author{
*Corresponding author \\ e-mail:tangxr@scau.edu.cn
}

(Received 20 $0^{\text {th }}$ Aug 2018; accepted 29 $9^{\text {th }}$ Nov 2018)

\begin{abstract}
A pot experiment was conducted to investigate the effects of paclobutrazol seed treatment on early growth, photosynthesis and physio-biochemical attributes on rice. The seeds of two rice cultivars i.e., Basmati-385 and Xiangyaxiangzhan were treated with paclobutrazol at $40 \mathrm{mg}$ per $5 \mathrm{~kg}$ of seeds $(\mathrm{T})$ whilst non-treated seeds were taken as control (CK). Result showed that the seedling length of Basmati-385 and Xiangyaxiangzhan was reduced by 32.16 and $26.85 \%$ when seeds were treated with paclobutrazol, however, net photosynthetic rate, maximal efficiency of PSII photochemistry $(F v / F m)$ and electron transport rate $(E T R)$ were increased by 25.34 and $7.98 \%, 4.22$ and $7.76 \%$ and 30.07 and $11.84 \%$ in Basmati-385 and Xiangyaxiangzhan, respectively. The malondialdehyde (MDA) contents were reduced up to $14 \%$ in both rice cultivars under paclobutrazol treatment. Furthermore, the activities of superoxide dismutase (SOD), peroxidase (POD), and catalase (CAT) were increased by 4.92 and $3.58 \%, 10.64$ and $14.42 \%, 31.19$ and $25.80 \%$ in paclobutrazol treated seeds than CK in both Basmati385 and Xiangyaxiangzhan, respectively. In addition, dry weight per unit seedling length was significantly correlated with SPAD values, root length, surface area, diameter, and root volume, net photosynthetic rate, chlorophyll a, chlorophyll b, carotenoids, Fv/Fm, ETR, antioxidant enzymes, soluble sugar, and soluble protein of both rice cultivars. However, negative correlations were also recorded between dry weight per unit seedling length and intercellular $\mathrm{CO}_{2}$, transpirational rates, non-photochemical quenching (NPQ) and malondialdehyde (MDA) contents in both Basmati-385 and Xiangyaxiangzhan. Hence, paclobuztrazol seed treatment enhanced photosynthetic and gas exchange attributes, physio-biochemical attributes and root morphological characters in rice. Keywords: antioxidants; seed dressing agent; net photosynthetic rate; rice seedlings; root morphology
\end{abstract}

\section{Introduction}

Paclobutrazol [(2RS, 3RS)-1-(4-chlorophenyl)-4, 4-dimethyl-2-(1, 2, 4-triazol -1-yl) pentan-3-ol] is a broad-spectrum gibberellin biosynthesis inhibitor which was developed by Imperial Chemical Industries (ICI) agrochemicals in 1986 (French et al., 1990). 
Paclobutrazol being a triazole, regulates the plant growth by antagonizing the hormone gibberellin biosynthesis by inhibiting the ent-kaurene oxidase enzyme which catalyses the oxidation of ent-kaurene to ent-kaurenoic acid in the terpenoid pathway for the production of gibberellins through inactivation of cytochrome P450-dependent monooxygenases (Fletcher et al., 2000). Paclobutrazol hinders gibberellic acid (GA) and endogenous indole acetic acid (IAA), whilst enhances abscisic acid (ABA), cytokinin and ethylene production within the plants (Fletcher et al., 2000; Zhang et al., 1998). Roles of auxins and cytokinins to promote growth and development of lateral and adventitious roots have been well reported (Fletcher et al., 2000; Zhang et al., 1998). The previous work has shown ample effectiveness of paclobutrazol and certain other triazoles for improving proline and soluble proteins, lignin contents, decreasing transpirational rate through the partial closure of stomata in several crops (Gopi et al., 2006; Özmen et al., 2003; Wang et al., 2015; Kamran et al., 2018). It is being widely used in many crops, mainly for producing shorter plant canopies whilst its antigibberellic behaviour has been reported in numerous plants (Özmen et al., 2003; Kamran et al., 2018; Upreti et al., 2013). Commonly, paclobutrazol and triazole regulate various plant morpho-physiological functions such as root growth stimulation, reduction in shoot growth (Jaleel et al., 2007; Manivannan et al., 2008), enhancement of chlorophyll contents, net photosynthetic rate, and carbohydrate content (Fletcher et al., 2000; Zhang et al., 1998), reduction of free-radical induced damage, improving antioxidant efficacy (Fletcher et al., 2000; Zhang et al., 1998). It further regulates cytokinin production and hinders abscisic acid biosynthesis (Fletcher et al., 2000).

In rice production system, paclobutrazol has been used to develop semi-dwarf and/or dwarf plant varieties to reduce lodging and to improve rice yield (Street et al., 1986). Furthermore, paclobutrazol treatment improved chlorophyll contents, root morphology plant architectural characters (Yim et al., 1997). Foliar applied paclobutrazol-induced growth regulations has been previously reported (Xiang et al., 2017), however a little is known about the seed treatment with paclobutrazol-induced modulations in morphophysiological and biochemical attributes of rice. Therefore, present study was conducted to investigate the effects of rice seed treatment with paclobutrazol on the morphological and physio-biochemical traits of rice.

\section{Materials and methods}

\section{Experimental details}

A pot experiment was conducted at Experimental Research Farm, College of Agriculture, South China Agricultural University, Guangzhou $\left(23^{\circ} 09^{\prime} \mathrm{N}, 113^{\circ} 22^{\prime} \mathrm{E}\right.$ and $11 \mathrm{~m}$ from mean sea level) China in September 2016. Seeds of two popularized aromatic rice cultivars i.e., Basmati-385 and Xiangyaxixangzhan were soaked in water for $12 \mathrm{~h}$ at room temperature and then put into the dark incubator at constant temperature $\left(35^{\circ} \mathrm{C}\right)$ for $12 \mathrm{~h}$ for germination. The following treatments were applied to germinated seed before sowing i.e., CK (no paclobutrazol treatment, taken as control) and $\mathrm{T}$ (paclobutrazol treatment (40 $\mathrm{mg}$ per $5 \mathrm{~kg}$ seeds). On $12^{\text {th }}$ September, 2016, 50 seeds per pot were sown according to the layout (Fig. 1). The average temperature was $28.5^{\circ} \mathrm{C}$ to $29.0^{\circ} \mathrm{C}$ during experimental period, while the average humidity was about $68-70 \%$. The experimental soil was collected from the paddy field and containing $1.14 \mathrm{~g}$ $\mathrm{kg}^{-1}$ total $\mathrm{N}, 0.92 \mathrm{~g} \mathrm{~kg}^{-1}$ total $\mathrm{P}, 16.65 \mathrm{~g} \mathrm{~kg}^{-1}$ total $\mathrm{K}, 77.35 \mathrm{mg} \mathrm{kg}^{-1}$ available $\mathrm{N}$, $61.34 \mathrm{mg} \mathrm{kg}^{-1}$ available $\mathrm{P}, 127.04 \mathrm{mg} \mathrm{kg}^{-1}$ available $\mathrm{K}$, and $23.34 \mathrm{~g} \mathrm{~kg}^{-1}$ organic matter. 
Before pot filling, the soil was kept under shade, air-dried, crushed and passed through $2 \mathrm{~cm}$ sieve.

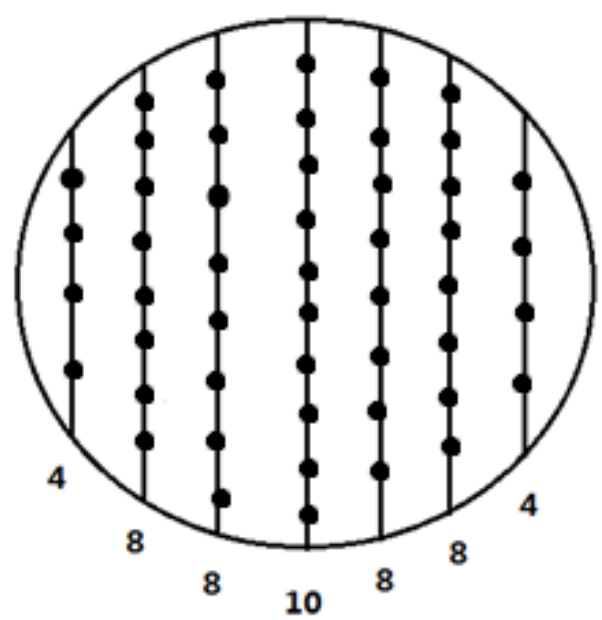

Figure 1. Layout of the sowing of seeds in pots

\section{Seedling growth parameters}

On $15^{\text {th }}$ October, seedlings were collected for determination of seedling growth parameters and physio-biochemical indices. The samples were uprooted manually, washed with tap water to clean deposits in the roots. The morphological attributes i.e., seedling length, stem base width, roots morphology, SPAD values and dry weight per seedling were recorded. Leaf SPAD values were recorded with a SPAD meter "SPAD502" and represented as relative chlorophyll contents. Roots morphology was determined by WinRHTZO Root System Analysis through scanning the roots of rice seedlings (Gu et al., 2010).

\section{Photosynthesis and chlorophyll fluorescence}

Photosynthesis and chlorophyll fluorescence were determined on the $32^{\text {th }}$ day after emergence. Portable photosynthesis system (LI-6400, LI-COR, USA) was used to determine net photosynthetic rate and gas exchange attributes i.e., stomatal conductance, intercellular $\mathrm{CO}_{2}$, and transpirational rates at 09:00-10:30 a.m. according to the standard method (Pan et al., 2015). Maximal efficiency of PSII photochemistry $(F v / F m)$, the quantum yield of PSII, non-photochemical quenching $(q N)$, electron transport rate $(E T R)$ were measured with an integrating fluorescence fluoro-meter (LI6400-40 leaf chamber fluorometer, Li-Cor, USA) under dark conditions.

\section{Physio-biochemical parameters}

Fresh leaves were separated from the plant for each treatment, double washed with distilled water and stored at $-80{ }^{\circ} \mathrm{C}$ till physio-biochemical analysis. The measurements were repeated in quadruplicate and mean values were calculated.

The photosynthetic pigments were determined by using $95 \%$ alcohol to extract contents (Lichtenthaler et al., 1987). The absorption was read at $665 \mathrm{~nm}, 652 \mathrm{~nm}$, $649 \mathrm{~nm}$ and $470 \mathrm{~nm}$. 
The malondialdehyde (MDA) contents were measured by reacting with thiobarbituric acid (TBA) (Schmedes et al., 1989). The absorbance of the reaction solutions were recorded at $532 \mathrm{~nm}, 600 \mathrm{~nm}$, and $450 \mathrm{~nm}$. The reaction solutions were calculated as: MDA content $\left(\mu \mathrm{mol} \cdot \mathrm{L}^{-1}\right)=6.45\left(\mathrm{OD}_{532}-\mathrm{OD}_{600}\right)-0.56 \mathrm{OD}_{450}$ and expressed as $\mu \mathrm{mol} \cdot \mathrm{g}^{-1} \mathrm{FW}$ (fresh weight).

Nitro blue tetrazolium (NBT) method was used to measure the superoxide (SOD, EC 1.15.1.1) activity $(\mathrm{Li}, 2000)$. The reaction mixture contained $1.75 \mathrm{ml}$ of buffer ( $\mathrm{pH} 7.8)$, $0.3 \mathrm{ml}$ of $130 \mathrm{mM} \cdot 1^{-1}$ methionine buffer, $0.3 \mathrm{ml}$ of $750 \mu \mathrm{mol} \cdot \mathrm{l}^{-1}$ NBT buffer, $0.3 \mathrm{ml}$ of $100 \mu \mathrm{mol} \cdot 1^{-1}$ EDTA-Na2 buffer, $0.3 \mathrm{ml}$ of $20 \mu \mathrm{mol} \cdot 1^{-1}$ lactoflavin and $0.05 \mathrm{ml}$ of enzyme extract. After reaction, the change in color was measured at $560 \mathrm{~nm}$. One unit of SOD activity is equal to the volume of extract needed to cause $50 \%$ inhibition of the color reaction.

The peroxidase (POD, EC 1.11.1.7) activity was measured by using enzyme extract. An aliquot of $50 \mu \mathrm{l}$ of extract was added to the reaction solution containing $1 \mathrm{ml}$ of $0.3 \% \mathrm{H}_{2} \mathrm{O}_{2}, 0.95 \mathrm{ml}$ of $0.2 \%$ guaiacol and $1 \mathrm{ml}$ of $50 \mathrm{mmol} \cdot \mathrm{L}^{-1}$ buffer $(\mathrm{pH} 7.0)$. The absorbance change of the brown guaiacol was recorded at $470 \mathrm{~nm}$ to calculate POD activity. One POD unit of enzyme activity was defined as the absorbance increase due to guaiacol oxidation by $0.01\left(\mathrm{U} \cdot \mathrm{g}^{-1}\right)$ (Luo et al., 2017). For catalase (CAT, EC 1.11.1.6) activity, an aliquot of $50 \mu \mathrm{l}$ of enzyme extract was added to the reaction solution containing $1 \mathrm{ml}$ of $0.3 \% \mathrm{H}_{2} \mathrm{O}_{2}$ and $1.95 \mathrm{ml}$ of $\mathrm{H}_{2} \mathrm{O}$. The change in absorbance was recorded at $240 \mathrm{~nm}$. One unit of enzyme activity was defined as the absorbance decrease by $0.01\left(\mathrm{U} \cdot \mathrm{g}^{-1} \mathrm{FW}\right)$ (Aebi et al., 1983).

The protein contents of leaves were estimated by using Coomassie Brilliant Blue G250 Reagent, and the absorbance was recorded at $595 \mathrm{~nm}$ and expressed as $\mu \mathrm{g} \cdot \mathrm{g}^{-1}$ of fresh weight (Bradford et al., 1976). The soluble sugar contents were determined by using anthrone-sulfuric acid method (Sun et al., 2010). The absorbance was recorded at $620 \mathrm{~nm}$ and expressed as $\mathrm{mg} \cdot \mathrm{g}^{-1}$ of fresh weight. Proline contents were estimated by using ninhydrin (Bates et al., 1973). The absorbance of the red chromophore in the toluene fraction was recorded at $520 \mathrm{~nm}$ and the amount of proline was estimated by comparing with a standard curve $(\mathrm{y}=0.0531 \mathrm{x}-0.0054)$ and expressed as $\mu \mathrm{g} \mathrm{g}^{-1} \mathrm{FW}$.

\section{Experimental design and statistical analyses}

There were 10 pots per treatment and all pots were arranged in completely randomized design (CRD). Data were analysed by a statistical software "Statistix 8.1" (Analytical Software, Tallahassee, FL, USA) whilst treatment means were compared by using least significant difference (LSD) test at 5\% probability level. Computer software "Origin 8.1" (Origin Lab Co., Northampton, MA, USA) was used for graphical representation.

\section{Results}

\section{Seedling growth parameters}

Seed treatment with paclobutrazol $(\mathrm{T})$ significantly $(\mathrm{P} \leq 0.05)$ affected seedling length, base stem width, SPAD values and dry weight per unit seedling length (Table 1). Comparing $\mathrm{T}$ with $\mathrm{CK}$, both Basmati-385 and Xiangyaxianzhan had lower seedling length whilst paclobutrazol enhanced SPAD values, base stem width and dry weight per unit seedling length. For example, 32.16 and $26.85 \%$ reduction in seedling length were 
recorded in Basmati-385 and Xiangyaxianzhan, respectively, whereas an increase of 34.46 and $17.36 \%$ in base stem width, 25.59 and $16.41 \%$ in SPAD values, and 38.81 and $51.41 \%$ in dry weight per unit seedling length were recorded in paclobutrazol seed treatment in treated seeds than control for Basmati-385 and Xiangyaxianzhan, respectively. Negative correlations were recorded between dry weight per unit seedling length in Basmati-385 and Xiangyaxiangzhan but significant positive correlations were observed between dry weight per unit seedling length and stem base width, SPAD values and root length (Table 2). The morphological appearance of treated and nontreated rice seedlings was presented in Figure 2.

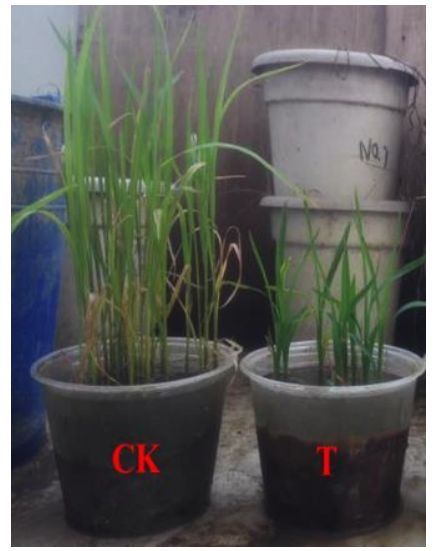

Figure 2. The physical appearance treated and non-treated rice seedlings. CK (non-treated); $T$ (seed treatment with paclobutrazol at $40 \mathrm{mg}$ per $5 \mathrm{~kg}$ seeds)

Paclobutrazol seed treatment also affected root morphology in terms of root length, surface area, diameter and volume (Table 1). Root length was 6.26 and $15.22 \%$ higher than CK in Basmati-385 and Xiangyaxiangzhan, respectively. Seedlings of Basmati-385 and Xiangyaxiangzhan in paclobutrazol seed treatment had 8.24 and $11.28 \%$ higher root diameter and 15.54 and $71.83 \%$ higher root volume, respectively than CK. Moreover, significant and positive correlations were observed between dry weight per unit seedling length, root surface area, root volume in response to paclobutrazol seed treatment (Table 2).

Table 1. Effect of seed dressing with paclobutrazol on rice seedling quality

\begin{tabular}{|c|c|c|c|c|c|c|c|c|c|}
\hline & & \multicolumn{4}{|c|}{ Shoot } & \multicolumn{4}{|c|}{ Root } \\
\hline & & $\begin{array}{l}\text { Height } \\
\text { (cm) }\end{array}$ & $\begin{array}{c}\text { Base } \\
\text { stem } \\
\text { width } \\
(\mathbf{m m})\end{array}$ & $\begin{array}{l}\text { SPAD } \\
\text { values }\end{array}$ & $\begin{array}{l}\text { Dry weight } \\
\text { per unit } \\
\text { seedling } \\
\text { length }(\mathrm{mg} \\
\left.\mathrm{cm}^{-1}\right) \\
\end{array}$ & $\begin{array}{l}\text { Length } \\
(\mathrm{cm})\end{array}$ & $\begin{array}{c}\text { Surface } \\
\text { area } \\
\left(\mathrm{cm}^{2}\right)\end{array}$ & $\begin{array}{l}\text { Diameter } \\
(\mathbf{m m})\end{array}$ & $\begin{array}{c}\text { Volume } \\
\left(\mathrm{cm}^{3}\right)\end{array}$ \\
\hline \multirow{2}{*}{ Basmati } & CK & $20.93 a$ & $6.21 b$ & $20.07 b$ & $5.86 b$ & $228.66 b$ & $16.60 \mathrm{~b}$ & $0.23 b$ & $0.10 \mathrm{~b}$ \\
\hline & $\mathrm{T}$ & $14.13 b$ & $8.44 \mathrm{a}$ & $24.79 \mathrm{a}$ & $7.84 \mathrm{a}$ & $242.97 \mathrm{a}$ & $18.48 \mathrm{a}$ & $0.25 \mathrm{a}$ & $0.12 \mathrm{a}$ \\
\hline \multirow{2}{*}{$\begin{array}{c}\text { Xiangyaxian } \\
\text { gzhan }\end{array}$} & $\mathrm{CK}$ & $17.90 \mathrm{a}$ & $5.34 b$ & $17.53 b$ & $3.27 b$ & $142.26 b$ & $9.83 b$ & $0.23 b$ & $0.05 b$ \\
\hline & $\mathrm{T}$ & $13.17 \mathrm{~b}$ & $6.14 \mathrm{a}$ & $20.57 \mathrm{a}$ & $4.97 \mathrm{a}$ & $163.90 \mathrm{a}$ & $13.77 \mathrm{a}$ & $0.25 a$ & $0.10 \mathrm{a}$ \\
\hline
\end{tabular}

Values sharing a common letter within a column don't differ significantly at $\mathrm{P} \leq 0.05$ according to least significant difference (LSD) test. CK (non-treated); $\mathrm{T}$ (seed treatment with paclobutrazol at $40 \mathrm{mg}$ per $5 \mathrm{~kg}$ seeds) 
Table 2. Correlation coefficients among dry weight per unit seedling length, height, stem base width, SPAD, length, surf area, average diameter and root volume

\begin{tabular}{c|c|c|c|c}
\hline & Basmati & $\boldsymbol{P}$ value & Xiangyaxiangzhan & $\boldsymbol{P}$ value \\
\hline Height & -0.9622 & 0.0021 & -0.9865 & 0.0003 \\
Stem base width & 0.9923 & 0.0001 & 0.9500 & 0.0037 \\
SPAD values & 0.9877 & 0.0002 & 0.9487 & 0.0039 \\
Length & 0.9461 & 0.0043 & 0.9821 & 0.0005 \\
Surf area & 0.8870 & 0.0184 & 0.9741 & 0.0010 \\
Average diameter & 0.9479 & 0.0040 & 0.8414 & 0.0357 \\
Root volume & 0.7036 & 0.1187 & 0.9755 & 0.0009 \\
\hline
\end{tabular}

\section{Net photosynthesis, gas exchange and chlorophyll contents}

Net photosynthetic rate and gas exchange attributes were substantially affected by paclobutrazol seed treatment. Both Basmati-385 and Xiangyaxiangzhan had 24.47 and $7.55 \%$ higher net photosynthetic rate (respectively) in paclobutrazol seed treatment compared with CK (Fig. 3a), whereas the both cultivars had decreased intercellular $\mathrm{CO}_{2}$ concentration (6.60 and $6.69 \%$ reduction in Basmati and Xiangyaxiangzhan, respectively) in paclobutrazol seed treatment as compared with CK (Fig. 3c).
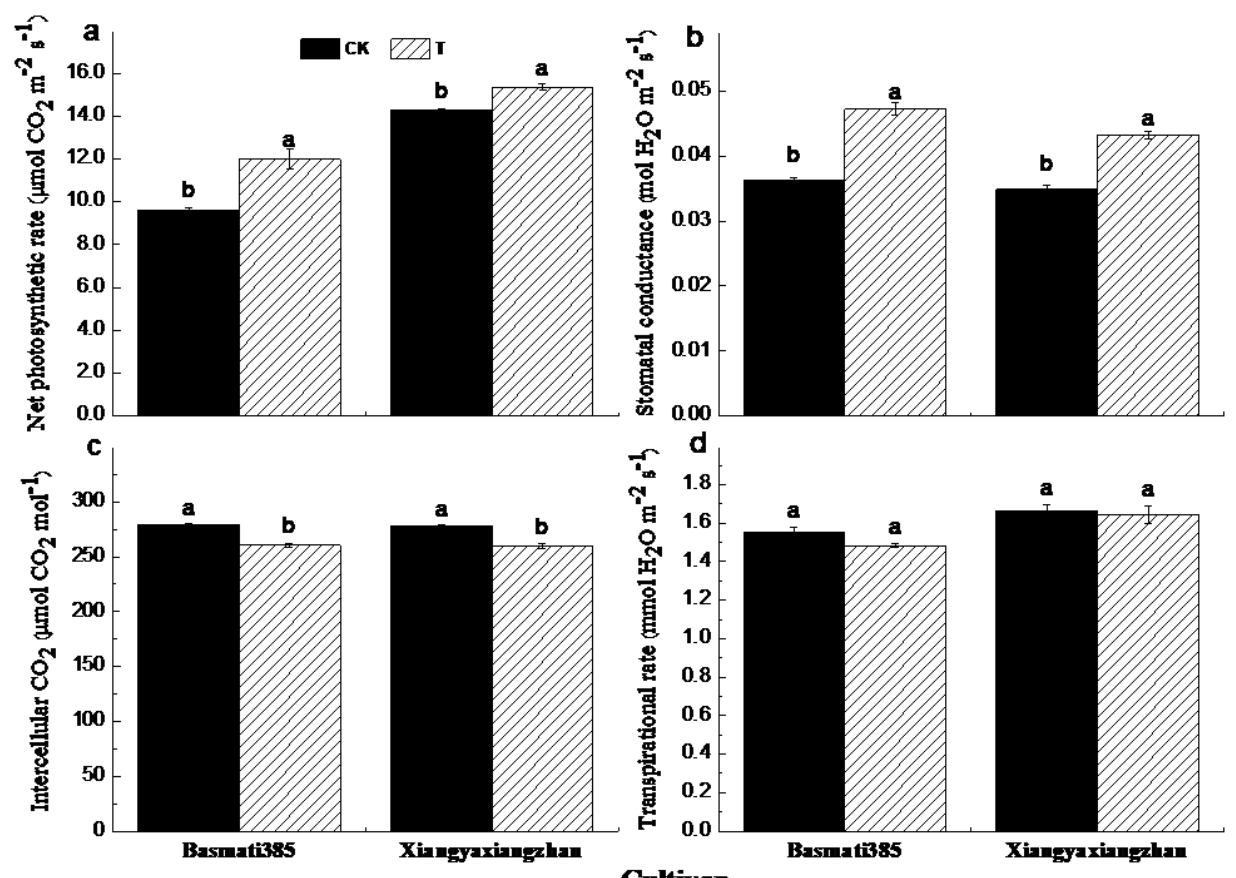

Figure 3. Effect of seed treatment with paclobutrazol on a) net photosynthesis, b) stomatal conductance, c) intercellular $\mathrm{CO}_{2}, d$ ) transpirational rate. Capped bars represent S.E. of three replicates. Means sharing a common letter do not differ significantly at $P \leq 0.05$ according to least significant difference ( $L S D)$ test. $C K$ (non-treated); $T$ (seed treatment with paclobutrazol at $40 \mathrm{mg}$ per $5 \mathrm{~kg}$ seeds)

However, there was no significant difference between $\mathrm{T}$ and $\mathrm{CK}$ for transpirational rates in both cultivars as shown in Figure 1d. In addition, the leaves of seedlings in 
paclobutrazol seed treatment had higher contents of chlorophyll a, chlorophyll b and carotenoid. Compared with CK, paclobutrazol seed treatment increased 50.19 and $11.55 \%$ chl a, 47.22 and $12.23 \%$ chl b contents, 56.53 and $9.45 \%$ in carotenoids and 44.53 and $12.48 \%$ in total chl contents of Basmati and Xiangyaxiangzhan, respectively (Fig. 4a-d). Furthermore, significant positive correlations were recorded between dry weight per unit seedling length and net photosynthetic rate, stomatal conductance, chl a, chl b, carotenoids and total chl contents in both rice cultivars, however, negative correlations were found among dry weight per unit seedling length and intercellular $\mathrm{CO}_{2}$ as well as transpiration rates in Basmati and Xiangyaxiangzhan (Table 3).
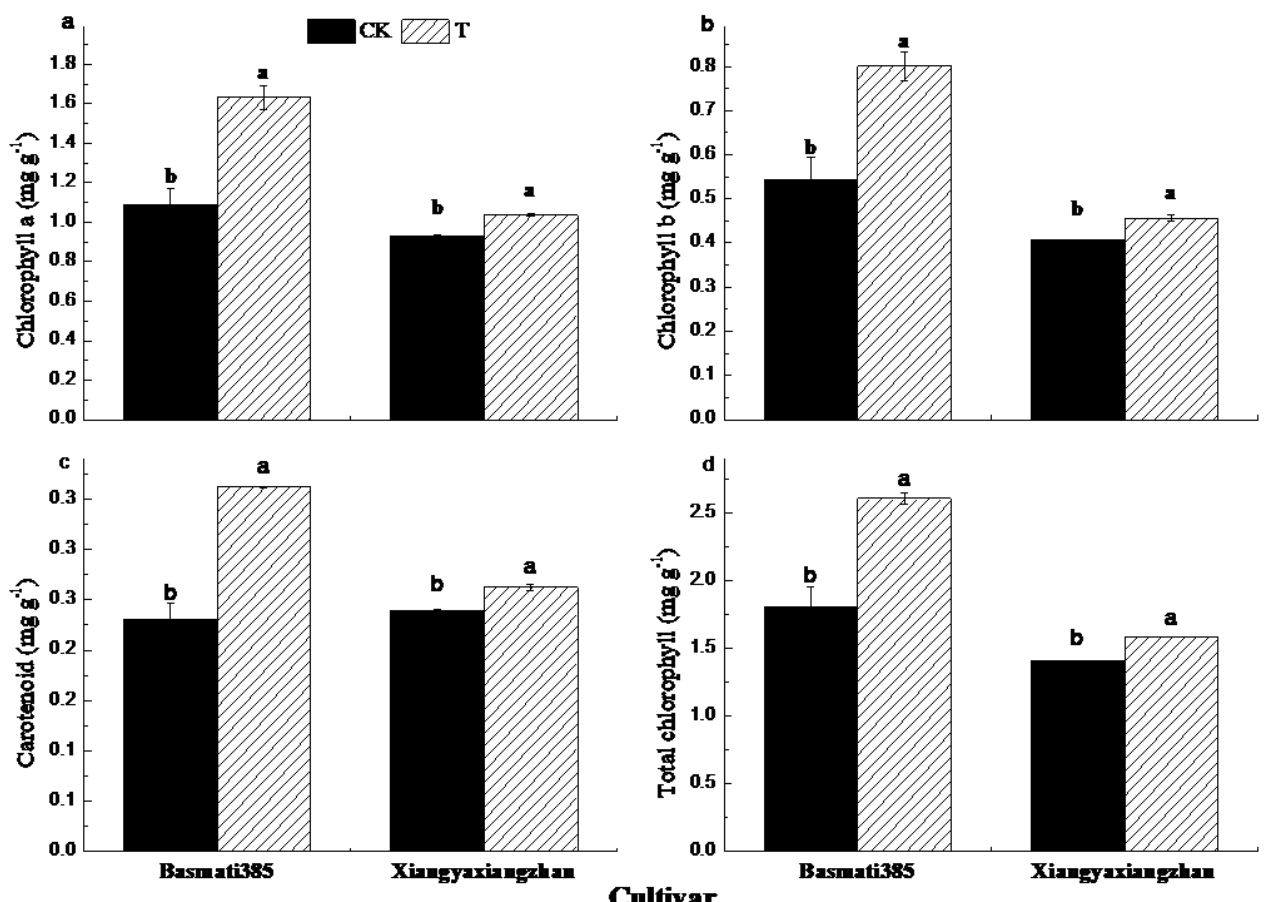

Figure 4. Effect of seed treatment with paclobutrazol on a) chlorophyll $a$, $b$ ) chlorophyll $b, c$ ) carotenoid, d) total chlorophyll. Capped bars represent S.E. of three replicates. Means sharing a common letter do not differ significantly at $P \leq 0.05$ according to least significant difference (LSD) test. CK (non-treated); $T$ (seed treatment with paclobutrazol at $40 \mathrm{mg}$ per $5 \mathrm{~kg}$ seeds)

Table 3. Correlation coefficients among dry weight per unit seedling length, net photosynthetic rate, stomatal conductance, intercellular $\mathrm{CO}_{2}$, transpirational rates, chlorophyll a, chlorophyll b, carotenoids and total chlorophyll

\begin{tabular}{c|c|c|c|c}
\hline & Basmati & $\boldsymbol{P}$ value & Xiangyaxiangzhan & $\boldsymbol{P}$ value \\
\hline Net photosynthetic rate & 0.9191 & 0.0096 & 0.9484 & 0.0039 \\
Stomatal conductance & 0.9936 & 0.0001 & 0.9712 & 0.0012 \\
Intercellular $\mathrm{CO}_{2}$ & -0.9722 & 0.0012 & -0.9473 & 0.0041 \\
Transpirational rates & -0.7883 & 0.0625 & -0.1930 & 0.7141 \\
Chlorophyll a & 0.9126 & 0.0111 & 0.9826 & 0.0004 \\
Chlorophyll b & 0.8906 & 0.0173 & 0.9717 & 0.0012 \\
Carotenoids & 0.9343 & 0.0063 & 0.9558 & 0.0029 \\
Total chlorophyll & 0.9011 & 0.0142 & 0.9951 & 0.0000 \\
\hline
\end{tabular}




\section{Chlorophyll fluorescence}

Significant differences in chlorophyll fluorescence parameters i.e., maximal efficiency of PSII photochemistry $(F v / F m)$, photochemical quenching $(q P)$, electron transport rate $(E T R), \mathrm{F}_{0}$ and $\mathrm{F}_{\mathrm{m}}$. Compared with $\mathrm{CK}$, an increase of 4.08 and $5.39 \%$ in $F v / F m, 15.72$ and $6.13 \%$ in $q P, 21.76$ and $31.36 \%$ in $F 0,21.45$ and $18.48 \%$ in $F m$, 32.50 and $10.39 \%$ in ETR was recorded for both Basmati-385 and Xiangyaxuangzhan, respectively (Fig. 5a-f). Moreover, significant decrease was recorded in nonphotochemical quenching $(N P Q)$ with the application paclobutrazol as compared with CK (Fig. 5e). Additionally, positive correlations were observed between dry weight per unit seedling length and $F v / F m, E T R, q P, F_{0}$ and $F_{m}$ whilst dry weight per unit seedling length was negatively associated with $N P Q$ (Table 4).
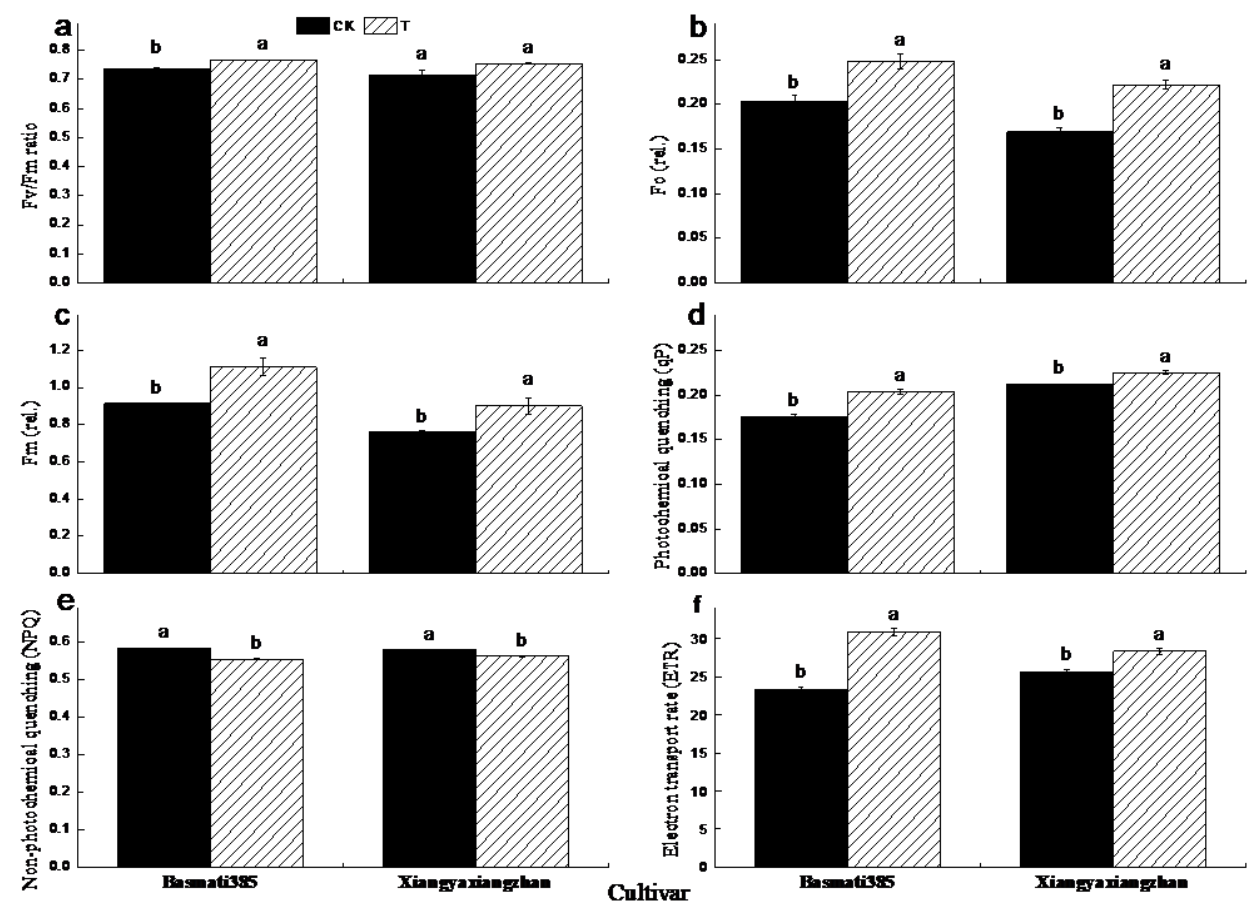

Figure 5. Effect of seed treatment with paclobutrazol on a) $F v / F m, b) F 0, c) F m, d$ ) photochemical quenching $(q P)$, e) Non-photochemical quenching $(N P Q), f)$ electron transport rate (ETR). Capped bars represent S.E. of three replicates. Means sharing a common letter do not differ significantly at $P \leq 0.05$ according to least significant difference (LSD) test. CK (nontreated); $T$ (seed treatment with paclobutrazol at $40 \mathrm{mg}$ per $5 \mathrm{~kg}$ seeds)

Table 4. Correlation coefficients among $F v / F m, E T R, N P Q, q P, F_{0}, F_{m}$

\begin{tabular}{c|c|c|c|c}
\hline Parameters & Basmati & $\boldsymbol{P}$ value & Xiangyaxiangzhan & $\boldsymbol{P}$ value \\
\hline$F v / F m$ & 0.9695 & 0.0014 & 0.7341 & 0.0967 \\
$E T R$ & 0.9832 & 0.0004 & 0.9244 & 0.0084 \\
$N P Q$ & -0.9511 & 0.0035 & -0.9688 & 0.0014 \\
$q P$ & 0.9618 & 0.0022 & 0.9477 & 0.004 \\
$F_{0}$ & 0.8980 & 0.0151 & 0.9591 & 0.0025 \\
$F_{m}$ & 0.8849 & 0.0191 & 0.8543 & 0.0303 \\
\hline
\end{tabular}




\section{Anti-oxidant responses, malodialdehyde, and soluble protein and sugar}

Paclobutrazol regulated anti-oxidative enzymatic activities in terms of SOD, POD and CAT, but lowered lipid per-oxidation (in terms of MDA production) and also induced changes in both protein and sugar contents in both rice cultivars (Fig. 6a-f). The POD, SOD and CAT activities were enhanced by 10.79 and $15.71 \%, 4.44$ and $3.57 \%$, and 31.30 and $26.48 \%$ in both Basmati-385 and Xiangyaxiangzhan, respectively compared with CK. On the other hand, Basmati-385 and Xiangyaxiangzhan showed a decrease of 16.43 and $14.33 \%$ in MDA contents, respectively with the application of paclobutrazol as compared with CK. Paclobutrazol seed treatment led to substantial improvements in soluble protein and soluble sugar contents of both rice cultivars. For instance, an increase of 8.87 and $28.38 \%$ in soluble protein and 19.57 and $25.44 \%$ in soluble sugar contents was recorded for Basmati-385 and Xiangyaxianzhan, respectively with the application of paclobutrazol. Furthermore, positive correlations were recorded among dry weight per unit seedling length and CAT, SOD, POD, soluble protein, proline and soluble sugar. However, negative correlation was recorded between dry weight per unit seedling length and MDA contents (Table 5).
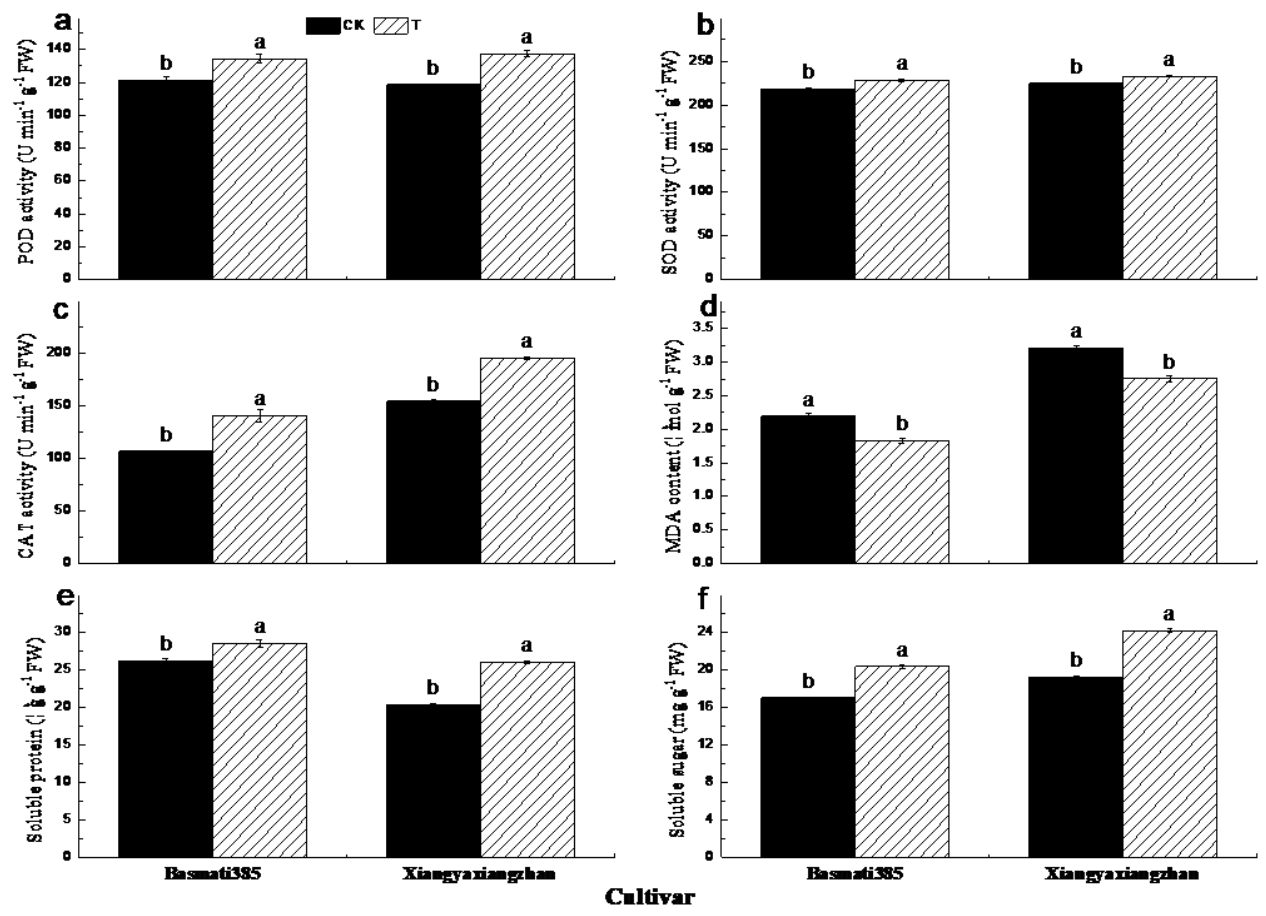

Figure 6. Effect of seed treatment with paclobutrazol on activity of a) POD, b) SOD, c) CAT, content of d) MDA, e) soluble protein, $f$ ) soluble sugar. Capped bars represent S.E. of three replicates. Means sharing a common letter do not differ significantly at $P \leq 0.05$ according to least significant difference ( $L S D)$ test

\section{Discussion}

Application of growth retardants modifies plant growth, development, root architecture, and physio-biochemical traits in crop plants. Previously, various troazoles have been studied as growth retardants and as anti-lodging agent of which paclobutrazole is a potential anti-gibberellic triazole (Peng et al., 2014). It inhibits the 
biosynthesis of endogenous GA, hence can be used for canopy management in various crops. It also provides relief against various abiotic stresses by regulating photosynthetic process, osmolyte production and activities of various enzymatic and non-enzymatic antioxidants (Hu et al., 2016). In this study, it was observed that seed treatment with paclobutrazol $(\mathrm{T})$ substantially reduced seedling length whilst improved base stem width, SPAD values and dry weight per unit seedling length and root morphology (Table 1). Moreover, significant and positive correlations were observed between dry weight per unit seedling length, root surface area, root volume in response to paclobutrazol seed treatment (Table 2). The result of reduction in seedling length and increase in the dry weight per unit seedling in paclobutrazol seed treatment are in agreement with Fletcher et al. (2000) who have indicated that paclobutrazol could induce semi-dwarf phenotype due to decreased production in growth promoting hormones which would help to reduce unnecessary vertical growth while promote productive growth. Previously, it was observed that semi-dwarf plants were able to avoid the serious grain losses from lodging. The roots help in the acquisition of plant nutrients from soil, so its morphological characteristics play an important role in plant growth (Yang et al., 2004). In present study, seed treatment with paclobutrazol stimulated root growth and thus improved the early growth of both rice cultivars. Increased root growth by paclobutrazol is associated with an increased level of endogenous cytokinin that promotes plant growth and development and delays senescence in plants (Fletcher et al., 2000). Seed treatment with paclobutrazol improved photosynthetic and gas exchange attributes and chlorophyll contents of both rice cultivars (Figs. 3 and 4), whereas dry weight per unit seedling length was positively correlated with net photosynthetic rate, stomatal conductance, chl a, chl b, carotenoids and total chl contents in both rice cultivars (Table 3). Photosynthesis is the process of converting light energy into chemical energy by synthesizing some organic compounds. Chlorophyll absorbs energy from the light, and energy is then used to convert carbon dioxide into carbohydrates (Connelly et al., 1997). The increased chl and carotenoid contents by paclobutrazol treatment may be due to improved root growth, which is the major site for cytokinin biosynthesis (Fletcher et al., 2000). They further reported that high levels of cytokinins may stimulate chlorophyll biosynthesis, and hence photosynthetic capacities of plants (Fletcher et al., 2000). Enhancement of photosynthetic pigment in plants by paclobutrazol has also been reported in barley (Özmen et al., 2003) and wheat (Hajihashemi et al., 2006). Trizole-induced modulations in leaf greenness, photosynthesis, chlorophyll biosynthesis and root morphological traits were noted in agronomic and horticultural crops (Hajihashemi et al., 2007).

Table 5. Correlation coefficients among dry weight per unit seedling length, CAT, MDA, $P O D$, SOD, protein, proline and sugar

\begin{tabular}{c|c|c|c|c}
\hline Parameters & Basmati & $\boldsymbol{P}$ value & Xiangyaxiangzhan & $\boldsymbol{P}$ value \\
\hline POD & 0.8576 & 0.0290 & 0.9802 & 0.0006 \\
SOD & 0.9500 & 0.0037 & 0.9651 & 0.0018 \\
CAT & 0.9581 & 0.0026 & 0.9968 & 0.0000 \\
MDA & -0.9787 & 0.0007 & -0.9698 & 0.0014 \\
Soluble protein & 0.8275 & 0.0421 & 0.9908 & 0.0001 \\
Soluble sugar & 0.9879 & 0.0002 & 0.9958 & 0.0000 \\
\hline
\end{tabular}


Seed treatment with paclobutrazol enhanced $F v / F m, q P, F 0, F m$ and ETR but decreased $N P Q$ in both Basmati-385 and Xiangyaxuangzhan as compared to $\mathrm{CK}$ (Fig. 5). These parameters were also positively correlated with dry weight per unit seedling length except NPQ which showed negative relations (Table 4). The improvement of $F v / F m, E T R$ and $q P$ manifested that paclobutrazol treatment have improved the activity of PSII reaction center and enhanced the energy efficiency. The results are in agreement with Hajihashemi et al. (2006) who have reported that high levels of cytokinins may stimulate chlorophyll biosynthesis which may result in improved activity of PS-II reaction center.

Paclobutrazol seed treatment further improved the antioxidant enzyme activities i.e., POD, SOD and CAT, as well as soluble protein and soluble sugars whilst reduced MDA contents (Fig. 6). Furthermore, positive correlations were recorded among dry weight per unit seedling length and CAT, SOD, POD, soluble protein, proline and soluble sugar whereas negative correlation was recorded between dry weight per unit seedling length and MDA contents. MDA production is an important indicator of oxidative stress. Lower MDA contents in paclobutrazol treatment indicated that its application may reduce the rate of lipid peroxidation. The results are similar to the previous studies because it can react with free amino acids and produce ethylene in cellular membranes (Rakwal et al., 2003) whilst it could imparts the characteristics of cellular membranes and results in increased ion leakage through cell membranes (Dash et al., 2002). When plants are subjected to external stress, reactive oxygen species (ROS) will accumulate inside which may cause oxidative damage to cellular membranes and organelles. On this occasion, proteins and sugar would help to maintain cellular structures and functions whilst anti-oxidants help for quenching ROS. For instance, SOD scavenges superoxide radical whereas POD and CAT involve in scavenging $\mathrm{H}_{2} \mathrm{O}_{2}$ (Pan et al., 2013). Thus paclobutrazol induced regulations in protein and sugar accumulation and anti-oxidative defence responses. This indicated that application of paclobutrazol will increase resistance ability of seedlings against stress. The fundamental mechanism of paclobutrazol for improving antioxidant defence system has not been fully understood (Sankar et al., 2007). Possibly, paclobutrazol might increase antioxidant efficiency via enzymatic and non-enzymatic antioxidants and the results are similar to former reports that paclobutrazol enhances antioxidant defence system by increasing the activities of different anti-oxidant enzymes i.e., SOD, CAT, APX, and POX and the contents of ascorbate, glutathione, and $\alpha$-tocopherol (Jaleel et al., 2007; Manivannan et al., 2008; Sankar et al., 2007). Enhancing antioxidant efficiency in plants by paclobutrazol has also been reported in Catharanthus roseus (Jaleel et al., 2007) and barley (Özmen et al., 2003). It is also possible that high antioxidant efficiency may result to prevent degradation of chlorophylls and carotenoids due to their higher ability to scavenge and trap ROS before damaging cells (Kong et al., 2017).

\section{Conclusion}

This study showed that seed treatment with paclobutrazol improved the shoot and root characters i.e., seedling length, base stem width, dry weight per unit seedling length, root length, root surface area, root diameter and root volume. Paclobutrazol treatment further modulated the photosynthetic and gas exchange traits, promoted the activities of antioxidants i.e., POD, SOD, and CAT whilst reduced MDA contents. Improved photosynthesis and anti-oxidant activities could lead to improved early 
growth of both rice cultivars; nonetheless optimization of paclobutrazol concentration for seed treatment of different crops is needed in future.

Acknowledgements. This study was supported by National Natural Science Foundation of China (31271646), National Key R\&D Program of China (2016YFD0700301), The World Bank Loan Agricultural Pollution Control Project in Guangdong (0724-1510A08N3684), The Technology System of Modern Agricultural Industry in Guangdong (2017LM1098) and Student's Platform for Innovation and Entrepreneurship Training Program (201810564029). The authors declare no conflicts of interest.

\section{REFERENCES}

[1] Aebi, H. (1983): Catalase in vitro. - Methods in Enzymology 105(105): 121-126.

[2] Bates, L. S., Waldren, R. P., Teare, I. D. (1973): Rapid determination of free proline for water-stress studies. - Plant \& Soil 1(39): 205-207.

[3] Bradford, M. M. (1976): A rapid and sensitive method for the quantitation of microgram quantities of protein utilizing the principle of protein-dye binding. Analytical Biochemistry s1-2(72): 248-254.

[4] Connelly, J. P., Müller, M. G., Bassi, R. et al. (1997): Femtosecond transient absorption study of carotenoid to chlorophyll energy transfer in the light-harvesting complex II of photosystem II. - Biochemistry 2(36): 281-287.

[5] Dash, S., Mohanty, N. (2002): Response of seedlings to heat-stress in cultivars of wheat: Growth temperature-dependent differential modulation of photosystem 1 and 2 activity, and foliar antioxidant defense capacity. - Journal of Plant Physiology 1(159): 49-59.

[6] Fletcher, R. A., Gilley, A., Sankhla, N., Davis, T. D. (2000) Triazoles as plant growth regulators and stress protectants. - Horticultural Reviews 24: 55-138.

[7] French, P., Matsuyuki, H., Ueno, H. (1990): Paclobutrazol: control of lodging in Japanese paddy rice. Pest management in rice. - Conference held by the Society of Chemical Industry, London, UK, 4-7 June 1990, pp. 474-485.

[8] Gopi, R., Lakshmanan, G. A., Panneerselvam, R. (2006): Triadimefon induced changes in the antioxidant metabolism and ajmalicine production in Catharanthus roseus (L.) G. Don. - Plant Science 2(171): 271-276.

[9] Gu, D. X., Tang, L., Cao, W. X., Zhu, Y. (2010): Quantitative analysis on root morphological characteristics based on image analysis method in rice. - Acta Agronomica Sinica 5(36): 810-817.

[10] Hajihashemi, S., Kiarostami, K., Enteshari, S., Saboora, A. (2006): The effects of salt stress and paclobutrazol on some physiological parameters of two salt-tolerant and salt-sensitive cultivars of wheat. - Pakistan Journal of Biological Sciences 9(7): 1370-1374.

[11] Hajihashemi, S., Kiarostami, K., Saboora, A., Enteshari, S. (2007): Exogenously applied paclobutrazol modulates growth in salt-stressed wheat plants. - Plant Growth Regulation 2(53): 117-128.

[12] $\mathrm{Hu}, \mathrm{Y} ., \mathrm{Yu}, \mathrm{W}$., Liu, T. et al. (2016): Effects of paclobutrazol on cultivars of Chinese bayberry (Myrica rubra) under salinity stress. - Photosynthetica 3(55): 1-11.

[13] Jaleel, C. A., Gopi, R., Manivannan, P., Panneerselvam, R. (2007): Responses of antioxidant defense system of Catharanthus roseus (L.) G. Don. to paclobutrazol treatment under salinity. - Acta Physiologiae Plantarum 3(29): 205-209.

[14] Kamran, M., Cui, W., Ahmad, I. et al. (2018): Correction to: Effect of paclobutrazol, a potential growth regulator on stalk mechanical strength, lignin accumulation and its relation with lodging resistance of maize. - Plant Growth Regulation 2(84): 1-2. 
[15] Kong, L., Ashraf, U., Cheng, S. et al. (2017): Short-term water management at early filling stage improves early-season rice performance under high temperature stress in South China. - European Journal of Agronomy 90: 117-126.

[16] Li, H. (2000): Principles and Techniques of Plant Physiology and Biochemistry Experiment. - Beijing Higher Education Press, Beijing, pp. 167-169.

[17] Lichtenthaler, H. K. (1987): Chlorophylls and carotenoids: Pigments of photosynthetic biomembranes. - Methods in Enzymology 1(148): 350-382.

[18] Luo, H., Zhong, Z., Nie, J., Tang, X. (2017): Effects of ultrasound on physiological characters, yield and quality of rice Yuejingsimiao. - China Rice 23(2): 64-67.

[19] Manivannan, P., Jaleel, C. A., Kishorekumar, A., Sankar, B., Somasundaram, R., Panneerselvam, R. (2008): Protection of Vigna unguiculata (L.) Walp. plants from salt stress by paclobutrazol. - Colloids \& Surfaces B Biointerfaces 2(61): 315-318.

[20] Özmen, A. D., Özdemír, F., Türkan, I. (2003): Effects of paclobutrazol on response of two barley cultivars to salt stress. - Biological Plantarum 2(46): 263-268.

[21] Pan, S., Rasul, F., Wu, L. et al. (2013): Roles of plant growth regulators on yield, grain qualities and antioxidant enzyme activities in super hybrid rice (Oryza sativa L.). - Rice 1(6): 9.

[22] Pan, S., Wen, X., Mo, Z. et al. (2015): Effects of nitrogen application and shading on yields and some physiological characteristics in different rice genotypes. - Rice Science 29(2): 141-149.

[23] Peng, D., Chen, X., Yin, Y. et al. (2014): Lodging resistance of winter wheat (Triticum aestivum L.): Lignin accumulation and its related enzymes activities due to the application of paclobutrazol or gibberellin acid. - Field Crops Research 2(157): 1-7.

[24] Rakwal, R., Agrawal, G. K., Kubo, A. et al. (2003): Defense/stress responses elicited in rice seedlings exposed to the gaseous air pollutant sulfur dioxide. - Environmental \& Experimental Botany 3(49): 223-235.

[25] Sankar, B., Jaleel, C. A., Manivannan, P., Kishorekumar, A., Somasundaram, R., Panneerselvam, R. (2007): Effect of paclobutrazol on water stress amelioration through antioxidants and free radical scavenging enzymes in Arachis hypogaea L. Colloids \& Surfaces B Biointerfaces 2(60): 229-235.

[26] Schmedes, A., Holmer, G. (1989): A new thiobarbituric acid (TBA) method for determining free malondialdehyde (MDA) and hydroperoxides selectively as a measure of lipid peroxidation. - Journal of the American Oil Chemists Society 6(66): 813-817.

[27] Street, J. E., Jordan, J. H., Ebelhar, M. W., Boykin, D. L. (1986): Plant height and yield responses of rice to paclobutrazol. - Agronomy Journal 2(78): 288-291.

[28] Sun, B., Zhang, W., Long, Z., Li, N., Wu, L., Gao, H. (2010): The sugar content analysis of codonopsis-astragalus root injection with anthrone-sulfuric acid method. Modern Chinese Medicine 2(163): 284-295.

[29] Upreti, K. K., Reddy, Y. T. N., Prasad, S. R. S., Bindu, G. V., Jayaram, H. L., Rajan, S. (2013): Hormonal changes in response to paclobutrazol induced early flowering in mango cv. Totapuri. - Scientia Horticulturae 2(150): 414-418.

[30] Wang, C., Hu, D., Liu, X. et al. (2015): Effects of uniconazole on the lignin metabolism and lodging resistance of culm in common buckwheat (Fagopyrum esculentum M.). - Field Crops Research 180): 46-53.

[31] Xiang, J., Wu, H., Zhang, Y. et al. (2017): Transcriptomic analysis of gibberellin- and paclobutrazol-treated rice seedlings under submergence. - International Journal of Molecular Sciences 10(18): 2225.

[32] Yang, C., Yang, L., Yang, Y., Ouyang, Z. (2004): Rice root growth and nutrient uptake as influenced by organic manure in continuously and alternately flooded paddy soils. - Agricultural Water Management 1(70): 67-81. 
[33] Yim, K. O., Kwon, Y.W., Bayer, D. E. (1997): growth responses and allocation of assimilates of rice seedlings by paclobutrazol and gibberellin Treatment. - Journal of Plant Growth Regulation 1(16): 35-41.

[34] Zhang, J., Sui, X., Li, B., Su, B., Li, J., Zhou, D. (1998): An improved water-use efficiency for winter wheat grown under reduced irrigation. - Field Crops Research 2(59): 91-98. 